\title{
Glomerulonephritis Induced in the Rabbit by Antiendothelial Antibodies
}

Seiichi Matsuo, Atsushi Fukatsu, Mary L. Taub, Peter R. B. Caldwell, Jan R. Brentjens, and Giuseppe Andres

Departments of Pathology, Microbiology, Medicine and Biochemistry, State University of New York at Buffalo, School of Medicine, Buffalo, New York 14214; the Renal Research Laboratory of the Buffalo General Hospital, Buffalo, New York 14203;

and the Department of Medicine, College of Physicians and Surgeons, Columbia University, New York 10032

\begin{abstract}
The effects of interaction between endothelial angiotensin converting enzyme (ACE) and goat anti-rabbit ACE (GtARbACE) antibodies were studied in rabbit glomeruli. By immunofluorescence ACE was not detectable in normal glomeruli. However, when kidneys were perfused with GtARbACE antibodies glomerular bound IgG was seven times higher than that of nonimmune IgG and granular deposits of goat IgG were found on the endothelium of glomeruli and arteries. Rabbits injected intravenous for $4 \mathrm{~d}$ with GtARbACE antibodies showed on day 1 granular deposits of goat IgG on the glomerular endothelium; from day 3 to 24 there was gradual development of subepithelial deposits of goat IgG, rabbit IgG and C3. When GtARbACE antibodies were similarly injected into proteinuric rabbits there was formation of subepithelial granular deposits of goat IgG and ACE. The results document that a glomerular endothelial antigen is redistributed in vivo by a specific ligand, an event associated with formation of immune deposits. Furthermore, if the glomerular permeability is artificially increased, immune complexes shed from nonglomerular endothelia into the circulation can contribute to form subepithelial immune deposits.
\end{abstract}

\section{Introduction}

The capillary wall of the renal glomerulus is composed of the visceral epithelial cells, the basement membrane, and the endothelial cells. The study of the interaction of antibodies with antigens present on the epithelial cells or in the basement membrane has provided considerable information concerning the morphological and immunocytochemical features of glomerular injury, as well as the in vivo processing of antibody to tissue antigens, and the characterization of mediators of inflammation. The earliest model studied was nephrotoxic glomerulonephritis, a proliferative and exudative injury induced by heterologous antibodies reactive with antigens of the basement membranes, including the glomerular basement membrane (1). The most recent model has been passive Heymann's glomerulonephritis (2-4), a membranous disease induced by heterologous antibody reactive with antigens expressed on the apical part of the epithelial cells of proximal convoluted tubules, and on the plasma mem-

Portions of this work were presented at the 17th Annual Meeting of the American Society of Nephrology (Washington, DC, 9-12 December, 1984) and published in abstract form (1984. Proc. Am. Soc. Nephrol. 119A).

Received for publication 25 August 1986 and in revised form 27 January 1987.

J. Clin. Invest.

(c) The American Society for Clinical Investigation, Inc.

$0021-9738 / 87 / 06 / 1798 / 14 \$ 1.00$

Volume 79, June 1987, 1798-1811 brane of glomerular visceral epithelial cells $(5,6)$. It is also evident that the glomerular endothelium can be rapidly and severely damaged by local binding of antibodies, mainly preformed xenoantibodies (7) or alloantibodies reactive with transplantation antigens (reviewed in 8). However, a model of glomerulonephritis induced by heterologous antibody to endothelial cells has not been established.

The present study was designed to analyze the glomerular changes resulting from the interaction of heterologous antibody to rabbit angiotensin converting enzyme (ACE) ${ }^{1}$ with rabbit endothelia in vivo. The data obtained show that the glomerular capillary wall can be the target of an antibody-mediated injury characterized by heterologous and autologous phases. Furthermore, the results show that when the glomerular permeability is artificially increased immune complexes shed from nonglomerular endothelia into the circulation may contribute to form glomerular subepithelial immune deposits. This new model of glomerulonephritis extends our knowledge on the interaction of antibody with endothelial antigens in the renal glomerulus and in other vascular districts.

\section{Methods}

Animals. 78 female New Zealand white rabbits (Beckens Farms, Sanborn, NY), each weighing $2.0-2.5 \mathrm{~kg}$, were used. They were allowed free access to food and water.

Induction of proteinuria in rabbits by administration of cationic bovine serum albumin (BSA). Crystalline BSA (Miles Laboratories, Inc., Elkhart, IN) was cationized using 1-ethyl-3[(3-dimethylaminopropyl)-carbodiimide hydrochloride] (Pierce Chemical Co., Rockford, IL) and anhydrous ethylenediamine (Fisher Scientific Co., Pittsburgh, PA) according to the method described by Border et al. (9). The isoelectric point (pI) was $\sim 9.5 .11$ rabbits were injected intravenously with $1 \mathrm{mg}$ of cationized BSA and $1 \mu \mathrm{g}$ of lipopolysaccharide B (Escherichia coli 026-B6, Difco Laboratories, Detroit, MI). After 7 d, a daily intravenous injection of 20 $\mathrm{mg}$ of cationized BSA was given for a period of $3 \mathrm{wk}$ (9). At this time the rabbit developed proteinuria (>300 mg/dl). The right kidney was removed and used for control. Three days after nephrectomy the rabbits were injected with goat anti-rabbit ACE (GtARbACE) $\gamma$-globulin or with normal goat $\boldsymbol{\gamma}$-globulin.

Captopril administration. SQ14225 Captopril (batch 02-842-230020, E. R. Squibb \& Sons, Inc., Princeton, NJ) was dissolved in water at the concentration of $0.25 \mathrm{mg} / \mathrm{ml}$. Since each rabbit drank $\sim 400 \mathrm{ml}$ of this solution every day, it was assumed that the amount of Captopril ingested was $\sim 100 \mathrm{mg}$ (40-50 mg/kg body wt per d). Captopril was continuously administered in this way for $7 \mathrm{~d}$ before serial intravenous injection of $\mathrm{ACE}$ antibody, and during the $4 \mathrm{~d}$ of antibody injections (total $11 \mathrm{~d}$ ). In

1. Abbreviations used in this paper: $\mathrm{ACE}$, angiotensin-coverting enzyme; ELISA, enzyme-linked immunosorbent assay; FITC, fluorescein isothiocyanate; GtARbACE, goat antirabbit ACE; HRP, horseradish peroxidase; IF, immunofluorescence; PLP, periodate lysine paraformaldehyde; SFFD, 50:50 mixture of Dulbecco's and Ham's F12 media containing $1.2 \mathrm{mg} /$ liter sodium bicarbonate and $15 \mathrm{mM}$ Hepes. 
four rabbits the Captopril administration was prolonged for $30 \mathrm{~d}$. Rabbits used for paired label isotope studies received Captopril for $8 \mathrm{~d}$.

GtARbACE antibody preparations. The preparation and characterization of GtARbACE $\gamma$-globulin, IgG, and Fab fragments was described previously $(10,11)$.

Cultures of renal epithelial cells. Primary cultures of proximal tubular cells were prepared according to the method described by Taub (12). New Zealand white rabbits (2-2.5 kg) were killed by cervical dislocation. The renal arteries were first perfused with PBS, and then with a $0.5 \%$ PBS suspension of magnetic iron oxide. The kidneys were removed, the cortex excised, and homogenized with a Dounce homogenizer. The homogenate was pressed through two nylon sieves with pores of 253 and $85 \mu \mathrm{m}$, respectively. The final material on top of the second sieve was resuspended in SFFD (50:50 mixture of Dulbecco's and Ham's F12 media containing $1.2 \mathrm{mg} /$ liter of sodium bicarbonate and $15 \mathrm{mM}$ Hepes) and the glomerular fraction was removed with a magnetic stirring bar. The remaining homogenate, formed mainly by proximal tubules, was incubated in SFFD containing $0.125 \mu \mathrm{g} / \mathrm{ml}$ collagenase (Clostridium histolyticum, type VII, Sigma Chemical Co., St. Louis, MO) and $0.025 \mathrm{mg} /$ $\mathrm{ml}$ soybean trypsin inhibitor (type 1-S, Sigma Chemical Co.) for $2 \mathrm{~min}$ at room temperature and centrifuged for $5 \mathrm{~min}$. The glomeruli were isolated from the glomerular portion of the homogenate by sieving with a 75- $\mu \mathrm{m}$ mesh stainless steel screen. Both proximal tubules and glomeruli were resuspended in modified Dulbecco's medium supplemented with $10 \%$ fetal calf serum and $0.66 \mathrm{U} / \mathrm{ml}$ insulin (Eli Lilly \& Co., Indianapolis, IN) and conditioned with $1 \%$ supernatant of a X63 murine myeloma cell culture (13). Culture dishes were placed in a $95 \%$ air and $5 \% \mathrm{CO}_{2}$ environment at $37^{\circ} \mathrm{C}$. After 6-9 d a nearly confluent outgrowth of cells was observed. The criteria used for identification of tubular epithelial cells were described previously (14). Cultures of glomerular epithelial cells were identified on the basis of morphological characteristics of the cells (15-17), and cytotoxic response to aminonucleoside of puromycin (Sigma Chemical Co.) (15). Moreover, both tubular and glomerular epithelial cells were stained by fluorescein isothiocyanate (FITC)-conjugated antibody to cytokeratin (17). In order to assess the effect of Captopril on the expression of ACE, selected confluent cultures of glomerular and tubular epithelial cells were incubated for $24-48 \mathrm{~h}$ with Captopril at concentrations of $0.5 \mu \mathrm{g}-10.0 \mu \mathrm{g} / \mathrm{ml}(18)$.

Perfusion of isolated kidney. The aim of these experiments was to measure the amount of kidney-fixing GtARbACE IgG and to evaluate whether Captopril administration increased the expression of ACE in the glomerular endothelium. The method of isolated kidney perfusion was used to avoid binding of GtARbACE IgG to other endothelia, especially to the pulmonary endothelium $(10,11)$. Rabbits were anesthetized with nembutal (Abbott Laboratories, North Chicago, IL) and thyamilal (Warner-Lambert Co., Morris Plains, NJ) and the left kidney was exposed. Both renal artery and vein were cannulated and all collateral arteries disconnected. The kidney was perfused with Tyrode buffer containing $0.25 \%$ bovine serum albumin (Sigma Chemical Co.) at a flow rate of 1.5 $\mathrm{ml} / \mathrm{min}$ using a peristaltic pump (model 1201, Harvard Apparatus, South Natick, MA). When the effluent became clear, the kidney was perfused for $7 \mathrm{~min}$, at the same flow rate, with either $5 \mathrm{mg}$ of GtARbACE IgG (three rabbits) or $5 \mathrm{mg}$ of normal goat IgG (three rabbits) mixed in 10 $\mathrm{ml}$ of Tyrode's buffer. The unbound IgG was removed by a final 15 -min perfusion with Tyrode's buffer. The kidney was then removed and cortical fragments were processed for immunofluorescence (IF) studies.

Paired label isotope studies. GtARbACE and normal goat IgG were labeled with ${ }^{125} \mathrm{I}$ and with ${ }^{131} \mathrm{I}$, respectively, using the chloramine $\mathrm{T}$ method (19). The iodinated preparations were extensively dialyzed against PBS and variable amounts of nonlabeled goat IgG were added in order to have comparable specific activities. The specific activity of ${ }^{125} \mathrm{I}$ GtARbACE IgG was $3.5-5.0 \times 10^{4} \mathrm{cpm} / \mu \mathrm{g}$ IgG, and that of ${ }^{131} \mathrm{I}$ normal goat IgG was $1.3-3.5 \times 10^{4} \mathrm{cpm} / \mu \mathrm{g}$ IgG. The respective left kidneys of three normal rabbits and of four rabbits treated for $8 \mathrm{~d}$ with Captopril were perfused, as described above, at a rate of $3 \mathrm{ml} / \mathrm{min}$ with a mixture containing $10 \mathrm{mg}$ of ${ }^{125} \mathrm{I}$ GtARbACE IgG, $10 \mathrm{mg}$ of ${ }^{131} \mathrm{I}$ normal goat IgG in $20 \mathrm{ml}$ of Hanks' solution. The time of perfusion was $7 \mathrm{~min}$. After additional 15 min perfusion with Hanks' solution the kidney was removed. One small fragment was used for IF. The remaining cortex was minced into small pieces and the glomeruli were separated by differential sieving through Nos. 100, 150, and 170 mesh brass sieves (Sargent-Welch Co., Skokie, IL) (20). More than $90 \%$ of the final preparations was formed by glomeruli. The glomeruli were extensively washed in PBS and transferred into glass scintillation vials for counting. The number of glomeruli present in each vial was counted and then the radioactivity was measured using a model 578 gamma scintillation spectrometer (Packard Instrument Co., Inc., Downers Grove, IL). The binding of GtARbACE IgG and normal goat IgG to $10^{4}$ glomeruli was calculated as follows $(20,21)$.

\section{(A) GtARbACE IgG $=\frac{\text { Count for }{ }^{125} I}{\text { Specific activity of }{ }^{125} \text { I GtARbACE IgG }}$}

$\times \frac{10^{4}}{\text { Number of glomeruli }} \mu \mathrm{g}$

(B) Normal Gt IgG $=\frac{\text { Count for }^{131} \text { I }}{\text { Specific activity for }{ }^{131} \text { I normal Gt IgG }}$

$\times \frac{10^{4}}{\text { Number of glomeruli }} \mu \mathrm{g}$

The specific binding of GtARbACE IgG was calculated according to the formula:

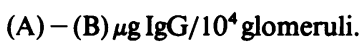

Intravascular injection of GtARbACE or normal goat serum preparations into rabbits. When ACE antibodies are injected intravenously a large and variable amount of antibody immediately binds to the lung because a large amount of ACE is expressed at the surface of the alveolar endothelium $(10,11)$. To assess the in vivo effect of high antibody delivery to the kidney two types of experiments were performed. In the first, the

Table I. Rabbits Studied with Systemic Administration of Immune or Nonimmune Preparations

\begin{tabular}{lclll}
\hline $\begin{array}{l}\text { Groups } \\
\text { of } \\
\text { rabbits }\end{array}$ & $\begin{array}{l}\text { Number } \\
\text { of } \\
\text { rabbits }\end{array}$ & $\begin{array}{l}\text { Captopril } \\
\text { administration }\end{array}$ & Injected preparation & $\begin{array}{l}\text { Day of renal } \\
\text { biopsy or } \\
\text { sacrifice* }\end{array}$ \\
\hline I & 7 & No & GtARbACE $\gamma$-globulin & $1-2$ \\
& 4 & Yes & GtARbACE $\gamma$-globulin & $1-2$ \\
& 12 & No & GtARbACE $\gamma$-globulin & $3-5$ \\
& 6 & Yes & GtARbACE $\gamma$-globulin & $3-5$ \\
& 14 & No & GtARbACE $\gamma$-globulin & $8-24$ \\
& 5 & Yes & GtARbACE $\gamma$-globulin & $8-24$ \\
& 3 & No & Normal goat $\gamma$-globulin & 1 \\
& 9 & No & Normal goat $\gamma$-globulin & $3-4$ \\
& 10 & No & Normal goat $\gamma$-globulin & $8-24$ \\
& 2 & Yes & Normal goat $\gamma$-globulin & $3-5$ \\
& 2 & Yes & Normal goat $\gamma$-globulin & $8-24$ \\
II & 1 & No & GtARbACE IgG & 2 \\
& 1 & No & Normal goat IgG & 2 \\
III & 1 & No & Fab fragments of & 2 \\
& & & GtARbACE IgG & \\
& 1 & No & Fab fragments of & 2 \\
& & & normal goat IgG & \\
IV & 8 & No & GtARbACE $\gamma$-globulin & $4-7$ \\
& 3 & No & Normal goat $\gamma$-globulin & $4-7$ \\
& & & &
\end{tabular}

* Day 1 is the first day of injection of the preparation of choice. The rabbits were injected for a maximum of $4 \mathrm{~d}$. 
immune and nonimmune serum preparations were directly injected into the abdominal aorta. In the second the immune and nonimmune serum preparations (Table I) were injected into a vein of the ear.

Injections into the abdominal aorta. A small silastic catheter $(0.020$ $\times$ OD 0.037, Dow Corning Corp., Midland, MI) was inserted from the right renal artery into the abdominal aorta, just above the left renal artery. Two rabbits were injected at the rate of $0.33 \mathrm{ml} / \mathrm{min}$ with $1 \mathrm{ml}$ of horseradish peroxidase (HRP)-conjugated GtARbACE $\gamma$-globulin diluted in five parts of PBS. The flow was controlled using the Harvard peristaltic pump. Two rabbits were injected in the same manner with HRP-conjugated normal goat $\gamma$-globulin. $10 \mathrm{~min}$ after the end of the injections, with the catheter still in place, a perfusion with Tyrode's buffer containing $1 \%$ glutaraldehyde was initiated. After $10 \mathrm{~min}$ of perfusionfixation the left kidney was removed and processed for immunoelectron microscopy. In addition, two rabbits were injected with $36 \mathrm{mg}$ of unlabeled GtARbACE $\gamma$-globulin, and two rabbits with $36 \mathrm{mg}$ of unlabeled normal goat $\gamma$-globulin. The renal tissue of these four rabbits was studied by IF microscopy with FITC-conjugated antibody to goat IgG, and the staining pattern was compared with the findings obtained by immunoelectron microscopy.

Injection into the veins of the ear. Four groups of rabbits were used in these experiments. The number of rabbits studied, the administration of Captopril, the type of the injected preparation, and the day when the samples of renal tissue were obtained are listed in Table I. Group I included rabbits injected for $4 \mathrm{~d}$ with GtARbACE $\boldsymbol{\gamma}$-globulin or with normal goat $\gamma$-globulin. The dose injected daily was: $8 \mathrm{mg} \times \mathbf{~ k g}$ of body weight on day $1,23 \mathrm{mg}$ on day $2,29 \mathrm{mg}$ on day 3 , and $19 \mathrm{mg}$ on day 4. Immune and nonimmune globulins were diluted in $12 \mathrm{ml}$ of sterile saline and slowly injected in an ear vein over a period of $8 \mathrm{~h}$. Group II included rabbits injected with GtARbACE IgG or with normal goat IgG. The doses were $8 \mathrm{mg} \times \mathrm{kg}$ of body weight on day 1 , and $23 \mathrm{mg}$ on day 2 . Group III included rabbits injected with Fab fragments of GtARbACE IgG or with Fab fragments of normal goat IgG. The doses were $5 \mathrm{mg}$ $\times \mathrm{kg}$ of body weight on day 1 and $16 \mathrm{mg}$ on day 2 . Group IV included rabbits rendered proteinuric by administration of cationic BSA (9), and subsequently injected with GtARbACE $\gamma$-globulin or with normal goat $\gamma$-globulin, as rabbits in group I. Kidney tissue obtained by surgical biopsy or at sacrifice was processed for morphological or immunocytochemical studies.

IF microscopy. FITC-conjugated IgG fractions from antisera to goat IgG, rabbit IgG and C3, guinea pig IgG, BSA, and affinity purified peroxidase-conjugated sheep anti-rabbit IgG were purchased from Cappel Laboratories (Cochranville, PA). Guinea pig anti-prekeratin IgG was purchased from Miles Laboratories (Naperville, IL). Biotinylated rabbit IgG antibody to goat IgG, and FITC-labeled avidin were purchased from Vector Laboratories, Inc., Burlingame, CA. All these antisera were monospecific when tested by immunoelectrophoresis and immunodiffusion. The conjugation of GtARbACE $\gamma$-globulin or IgG with FITC (22) and the methods of direct and indirect IF microscopy were performed as previously described (23). Isolated glomeruli and cultured glomerular and tubular cells were fixed with $2 \%$ paraformaldehyde or methanol for 15 min at $4^{\circ} \mathrm{C}$, washed three times with PBS and incubated with FITCGtARbACE $\gamma$-globulin. Other cultures were first incubated with a primary antiserum (GtARbACE IgG or guinea pig anti-prekeratin) or with normal goat IgG for $30 \mathrm{~min}$; after washing in PBS the cells were then stained for $30 \mathrm{~min}$ at room temperature with FITC-antisera to goat or guinea pig IgG. The sections and the cultured cells were mounted in a medium containing $p$-phenylenediamine (24), and examined with a Leitz Orthlux microscope equipped with epifluorescence optics and appropriate filters. Presence of GtARbACE IgG in the sera of rabbits was assessed by indirect IF microscopy using sections of normal rabbit lung and kidney fixed in cold acetone, incubated with serum samples, and subsequently stained with FITC-sheep anti-goat IgG.

\section{Immunoelectron microscopy}

In vitro method. The artery of the left kidney was cannulated and the organ was perfused with the periodate-lysine paraformaldehyde (PLP) fixative (25) for $10 \mathrm{~min}$. Small fragments of cortex were excised and further fixed by immersion in PLP fixative for $4-6 \mathrm{~h}$ at $4^{\circ} \mathrm{C}$. The tissue was washed in PBS containing 4\% sucrose for $60 \mathrm{~h}$, with several changes. The last change was $1 \mathrm{~h}$ in PBS containing 4\% sucrose and 7\% glycerol. The tissue was embedded in OCT (Miles Laboratories) and frozen in liquid nitrogen. Sections $8 \mu \mathrm{m}$ in thickness were cut in a cryostat and mounted on egg-albumin coated slides, dried at room temperature, and incubated for $40 \mathrm{~min}$ at $4^{\circ} \mathrm{C}$ in PBS containing $0.05 \%$ sodium borohydride. For detection of goat or rabbit IgG the sections were first incubated with normal rabbit or goat serum diluted 1:20 in PBS, then with affinity purified rabbit anti-goat IgG or affinity purified goat anti-rabbit IgG (Cappel Laboratories) at the dilution of $1: 4$ for $1 \mathrm{~h}$ at room temperature. After washing in PBS the sections were incubated with immune complexes formed by HRP and goat anti-HRP or by HRP and rabbit anti-HRP (Cappel Laboratories), at the dilution of $1: 15$ for $1 \mathrm{~h}$ at room temperature. Control sections were incubated with rabbit or goat IgG diluted 1:40 instead of with rabbit anti-goat or goat anti-rabbit IgG. After fixation in $2.5 \%$ glutaraldehyde for $30 \mathrm{~min}$ at $4^{\circ} \mathrm{C}$, all sections were incubated for $10 \mathrm{~min}$ at room temperature with $0.05 \mathrm{M}$ Tris- $\mathrm{HCl}$ buffer $\mathrm{pH} 7.6$ containing $0.027 \%$ diamenobenzidine hydrochloride (Sigma Chemical Co.), and then for another 2.5-5 min, with the same solution containing $\mathrm{H}_{2} \mathrm{O}_{2}$ at a final concentration of $0.005 \%(26,27)$. The sections were postfixed in $1 \%$ osmium tetroxide, dehydrated in alcohol and flat-embedded in Epon 802-Araldite. The thin sections, cut with an ultramicrotome, were studied with an electron microscope (JEOL 100S, JEOL USA, Peabody, MA) without additional staining.

In vivo method. GtARbACE and normal goat $\gamma$-globulins were conjugated with HRP (type VI, Sigma Chemical Co.) according to the method of Nakane and Kawaoi (28). The HRP activity of the conjugated $\gamma$ globulin preparations was measured in a spectrophotometer (DB-G, Beckman Instruments, Inc., Fullerton, CA) at an activation wave length of 280 and of $403 \mu \mathrm{m}$. At a dilution of 1:10 the optical densities of HRPconjugated GtARbACE $\gamma$-globulin were 0.365 and 0.180 , respectively; the optical densities of HRP-conjugated normal goat $\boldsymbol{\gamma}$-globulin were 0.340 and 0.170 , respectively. These two HRP-conjugates were injected into the abdominal aorta, as described. After preliminary fixation of the left kidney by perfusion, small fragments of cortical tissue were excised and further fixed for $4 \mathrm{~h}$ at $4^{\circ} \mathrm{C}$ in $1 \%$ glutaraldehyde. The tissue was washed in several changes of PBS for $2 \mathrm{~d}$ and $20-\mu \mathrm{m}$ thick sections were cut using an Oxford Vibratome model G (Oxford Industries, San Mateo, CA). The sections were processed for the Graham and Karnovsky's reaction $(26,27)$ as described (11).

Morphologic light and electron microscopy studies. Fragments of kidney tissue were fixed in $10 \%$ buffered formalin and embedded in paraffin. 3- $\mu \mathrm{m}$ thick sections stained with hematoxylin-eosin and periodic acid Schiff, were studied by light microscopy. Additional light microscopy studies were performed using $1-\mu \mathrm{m}$ thick sections of tissue, processed for electron microscopy as described below, and stained with toluidine blue. Tissue for electron microscopy was fixed with the Karnovsky's paraformaldehyde-glutaraldehyde solution (29), postfixed in $1 \%$ osmium tetroxide and embedded in Epon 812-Araldite. Thin sections stained with uranyl acetate and lead citrate were studied with a JEOL $100 \mathrm{~S}$ electron microscope.

Elution of goat IgG from renal glomeruli. Renal eluates were obtained from rabbits injected with GtARbACE $\gamma$-globulin and from rabbits injected with normal goat $\gamma$-globulin. The kidneys were removed at the end of day 3. Renal cortex was minced in PBS, and glomeruli were separated from tubules by sieving (30). The number of glomeruli was determined by counting with a hemocytometer, and the amount of protein was determined by the Bradford method with the kit purchased from Bio-Rad Laboratories (Richmond, CA). Glomeruli were subjected to acid elution ( $0.02 \mathrm{M}$ citrate, $\mathrm{pH} 3.2)$ as described by Woodroffe and Wilson (31). The eluate was collected after $1 \mathrm{~h}$ and again after an additional $3 \mathrm{~h}$ of incubation. The $\mathrm{pH}$ was restored to 7.4 and the $\gamma$-globulin fractions wee precipitated with $50 \%$ ammonium sulfate. The eluates were adjusted to the amount of protein eluted per 38,000 glomeruli and to an equal concentration of $\operatorname{lgG}(80 \mathrm{ng} / \mathrm{ml})$. The ACE reactivity of the $\gamma$ - 
globulin preparations was assessed by enzyme-linked immunosorbent assay (ELISA).

ELISA. The tests were performed according to the method of Engvall and Perlmann (32), using goat IgG or ACE as antigens. For the measurement of rabbit anti-goat IgG present in the sera of rabbits injected with GtARbACE IgG or with normal goat IgG, DEAE-purified goat IgG (Miles Laboratories) was diluted $10 \mathrm{mg} / \mathrm{ml}$ in Voller's buffer and $500 \mathrm{ng}$ was added to each well of the microtiter plate (Dynatech, Alexandria, VA). After overnight incubation at $4^{\circ} \mathrm{C}$ the plates were washed with PBS containing $0.05 \%$ Tween 20 (PBS-T), and rabbit sera to be tested were added using 1:40 dilution in PBS-T. After incubation and washings 100 $\mu l$ of HRP-conjugated sheep anti-rabbit IgG (Cappel Laboratories) diluted 1:500 in PBS-T was added to each well. $100 \mu \mathrm{l}$ of $1 \mathrm{mg} / \mathrm{ml}$ suspension of $O$-phenylene-diamine (Sigma Chemical Co.) in citrate buffer containing $0.001 \% \mathrm{H}_{2} \mathrm{O}_{2}$ was then added to each well. For the study of the reactivity of glomerular eluates $500 \mathrm{ng}$ of rabbit ACE (a generous gift of Dr. Barton Holmquist [33]) were added to each well. Serial PBS-T dilutions of the eluates were added, followed by biotin-conjugated rabbit anti-goat IgG diluted 1:1,000 for $1 \mathrm{~h}$, and by HRP-conjugated avidin, diluted 1:2,000, for $15 \mathrm{~min}$. After $20 \mathrm{~min}$ the reactions were stopped by addition of $2 \mathrm{M}$ sulphuric acid and absorbance at $492 \mu \mathrm{m}$ (OD 492) was determined using a Biotek Microtitration Plate Reader, model EL 310 (Burlington, VT). Control experiments for rabbit anti-goat IgG included (a) inhibition of the binding of rabbit anti-goat IgG to the goat IgG-coated wells, by preincubation of $500 \mu \mathrm{l}$ of rabbit serum containing antibody to goat IgG with $25 \mu \mathrm{l}$ of a $1 \mathrm{mg} / \mathrm{ml}$ of goat IgG; and $(b)$ incubation of $500-\mu$ laliquots of rabbit anti-goat $\mathrm{IgG}$ with $25 \mu \mathrm{l}$ of $1 \mathrm{mg} / \mathrm{ml}$ of human $\mathrm{IgG}$, or with 20 $\mu$ l of PBS. All these control samples were assayed as described above. The eluates obtained from glomeruli of rabbits injected with the immune or nonimmune goat IgG preparations were similarly treated for comparison of ACE reactivity.

Circulating immune complexes. Circulating immune complexlike material was measured by the Raji cell radioimmunoassay (34) as previously described (35).

Measurement of proteinuria. For the calculation of the 24-h urinary protein excretion, urine was collected overnight in metabolic cages, allowing the rabbits access to water but not to food. The biuret test was performed to measure the amount of protein in the urine sample (36).

\section{Results}

Expression of ACE in cultured rabbit glomerular and tubular epithelial cells. $95-99 \%$ of the cells that had grown out from glomeruli or proximal tubules at day 9 in primary cultures had the characteristics of glomerular or tubular epithelial cells (1416). Isolated glomeruli and cultured glomerular cells did not react with GtARbACE IgG (Fig. 1). Incubation with various concentrations of Captopril did not induce detectable expression of ACE on their surface. By way of contrast, binding to GtARbACE was observed, in all cultures, at the surface of proximal tubular cells, especially in the microvilli (Fig. 2).

Expression of ACE in sections of rabbit kidney. The study by direct and indirect IF technique of kidney sections obtained from normal rabbits showed deposits of ACE in the brush border of proximal convoluted tubules, and in the endothelium of small arteries but not in glomerular structures or in peritubular capillaries (Fig. 3). Likewise, ACE was not detectable in glomeruli of rabbits treated with Captopril. In these Captopril-treated rabbits, however, the amount of ACE expressed in the brush border of proximal convoluted tubules was apparently decreased, whereas ACE on the endothelium of the arteries was unchanged.

Perfusion of isolated kidney. When isolated kidneys were
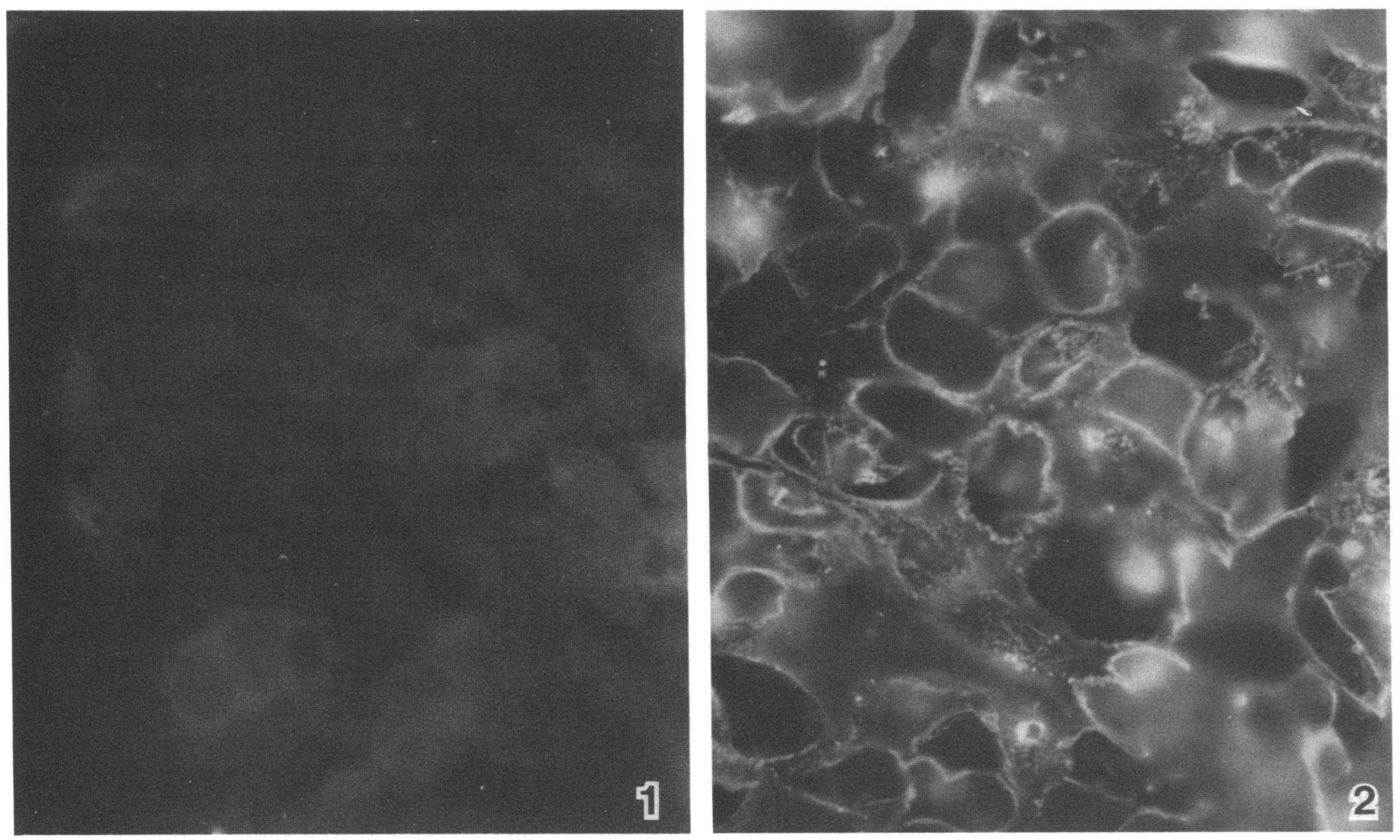

Figures 1 and 2. (Fig. 1) Culture of rabbit glomerular epithelial cells incubated with FITC-GtARbACE IgG. ACE is not detectable. $\times 800$. (Fig. 2) Culture of rabbit tubular epithelial cells incubated with FITC-GtARbACE IgG. ACE is expressed as the cell surface. Larger amount of the label is seen in a vertical plane at the edges of the cells and in microvilli. $\times 800$. 


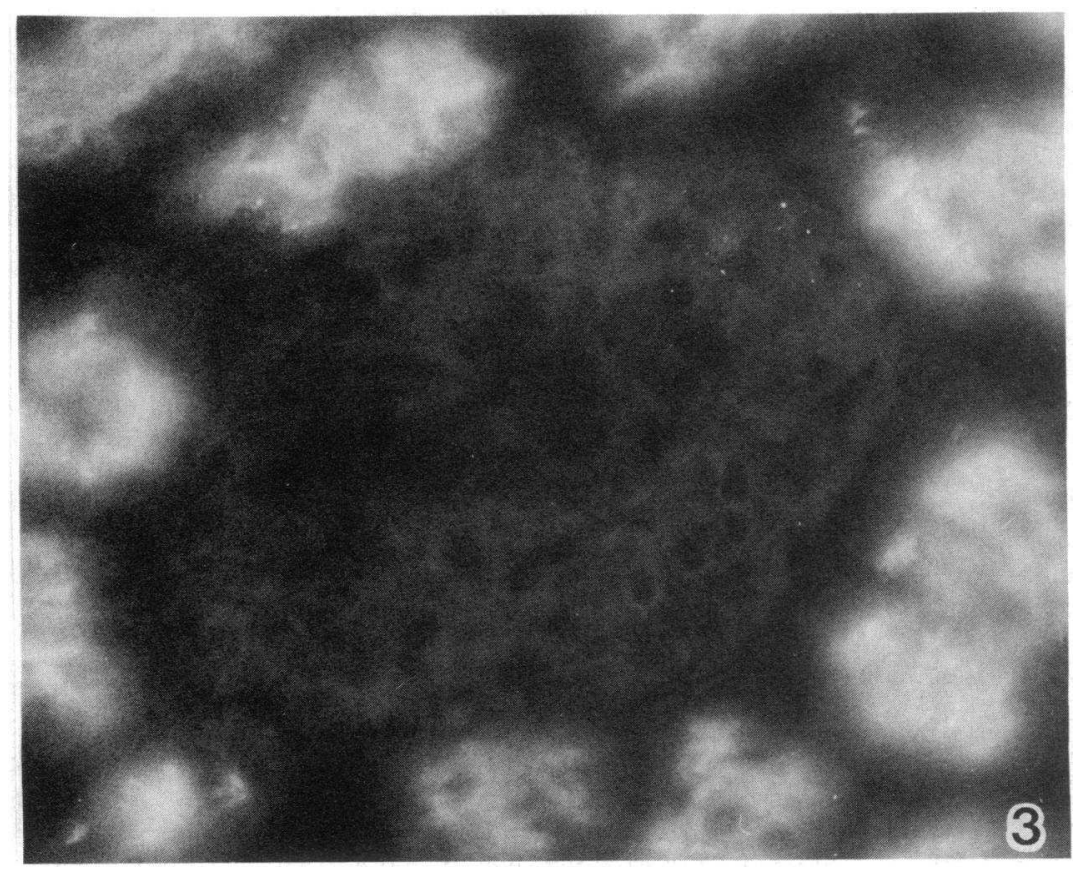

Figure 3. Section of normal rabbit kidney tissue stained with FITC-GtARbACE IgG. Deposits of ACE are detected in the brush border of the proximal convoluted tubules, but not in the glomerulus. $\times 600$. perfused with GtARbACE IgG fine granular deposits of goat IgG were found along the endothelium of glomerular capillaries (Fig. 4) and, especially, of the glomerular arterioles. Binding of goat IgG to the endothelium of peritubular capillaries was not observed. Deposits of goat IgG were not present in the endothelia of kidneys perfused with normal goat IgG.

Paired label isotope studies. The results of the studies designed to quantitate the amount of goat IgG bound to renal glomeruli after perfusion of isolated kidney are given in Table II. The amount of GtARbACE IgG bound to glomeruli was approximately seven times higher than that of normal goat IgG, in both untreated rabbits and those receiving Captopril. There was a twofold increase $(P<0.001)$ in binding of GtARbACE IgG to glomeruli of rabbits treated with Captopril. IF on fragments of renal tissue used for paired label isotope studies showed that goat IgG was localized in glomeruli, arteries, and arterioles, but not in the brush border of proximal convoluted tubules.

\section{Intravascular injection of GtARbACE or normal goat serum preparations into rabbits}

Injection into the abdominal aorta. When HRP-conjugated GtARbACE $\gamma$-globulin was injected into the abdominal aorta, just above the left renal artery, small aggregates of reaction product were found on the plasma membranes of glomerular endothelial cells (Fig. 5). A more diffuse and stronger labeling was observed on the endothelial plasma membranes of arteries and arterioles, including the coated pits (Fig. 6). When rabbits were similarly injected with HRP-conjugated normal goat $\boldsymbol{\gamma}$-globulin a glomerular deposition of reaction product was never observed. Parallel studies performed by IF after injection of unlabeled GtARbACE $\boldsymbol{\gamma}$-globulin or unlabeled normal goat $\boldsymbol{\gamma}$-globulin provided results comparable to those obtained by immunoelectron microscopy, i.e., fine, granular deposits of goat IgG on glomerular endothelium, and more diffuse and stronger deposits on the endothelium of the arteries (Fig. 7), exclusively in rabbits injected with the immune preparation.
Injection into a vein of the ear (Table I). $1 \mathrm{~d}$ after the beginning of the injections of GtARbACE $\gamma$-globulin (group I) or IgG (group II) fine, granular, deposits of goat IgG were observed by IF on the glomerular endothelium (Fig. 8). One of the four rabbits studied on day 1 and all rabbits studied on day 2 had similar deposits of C3. Deposits of ACE were not detectable in glomeruli stained with FITC-GtARbACE $\gamma$-globulin. By light and transmission electron microscopy an increased number of polymorphonuclear leukocytes in the lumen of glomerular capillaries and numerous endothelial blebs were seen (Fig. 9).

During days 3-5 samples of renal tissue were obtained from rabbits in group I. Diffuse, almost linear deposits of goat IgG were consistently detected by IF microscopy along the glomerular capillary walls (Fig. 11, inset). In specimens obtained on day 3 and 4 and studied by immunoelectron microscopy for presence of goat IgG, the reaction product was localized at the base of the foot processes and in the filtration slits (Fig. 12). Deposits of ACE and of rabbit IgG and C3 were not detectable in this location. The most consistent abnormality seen by light (Fig. 10) and transmission electron microscopy (Fig. 11) was the swelling of the endothelium, which appeared devoid of organelles and contained numerous blebs. A moderate number of macrophages and platelets was present in the lumen of the capillaries, while the number of polymorphonuclear leukocytes was decreased, as compared with day 1 and 2 . The morphologic changes were most severe on day 3 ; the severity and extent of these lesions subsided from day 5 onward.

From day 8 to 24 the most remarkable change observed in the kidney of group I rabbits was the presence of well defined interrupted linear, occasionally finely granular, deposits of goat IgG, rabbit IgG (Fig. 16), and C3 (Fig. 17) along the glomerular capillary walls. ACE was not detectable by direct IF. In specimens obtained at various intervals of time between day 8 and 24, and studied by immunoelectron microscopy for presence of goat IgG, the reaction product was found in the filtration slits (Fig. 13), less frequently at the base of the foot processes or, in the form 

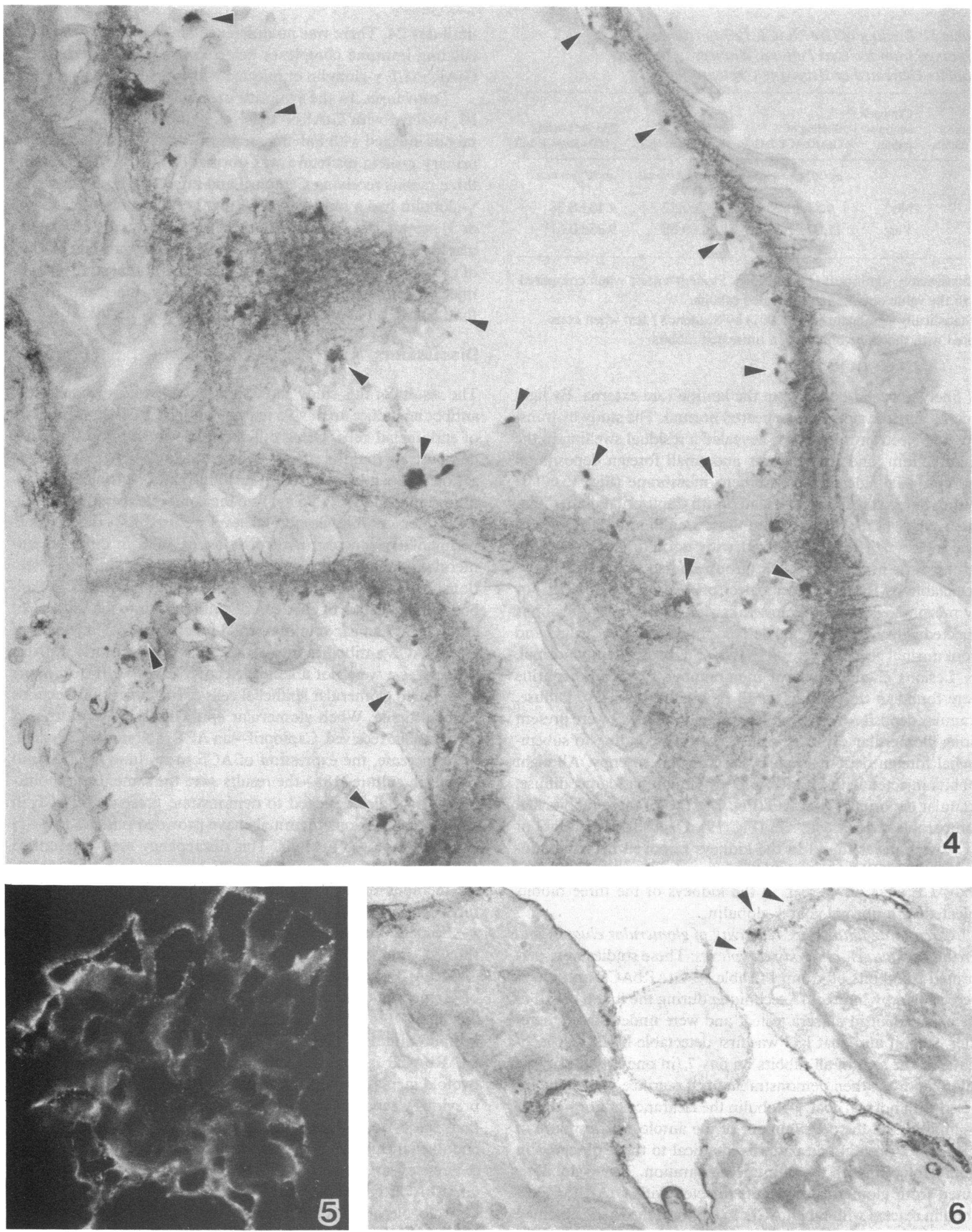

Figures 4 through 6. (Fig. 4) Electron micrograph showing the results of an experiment performed by perfusing the kidney of a rabbit with HRP-conjugated GtARbACE $\gamma$-globulin, as described in Methods. Patchy deposits of reaction product (arrowheads) are seen on the surface of glomerular endothelial cells, and in the endothelial fenestrae. $\times 25,000$. (Fig. 5) Section of rabbit kidney perfused with GtARbACE IgG, and stained with FITC-rabbit anti-goat IgG. Fine, granular de- posits of goat IgG are present along the inner part of the glomerular capillary walls. $\times 400$. (Fig. 6) Electron micrograph showing deposits of goat IgG on the plasma membrane of endothelial cells in the artery of a kidney perfused with GtARbACE $\gamma$-globulin and studied by immunoperoxidase electron microscopy. The arrowheads indicate deposits of reaction product, presumably in the coated pits. $\times 14,000$. 
Table II. Binding of GtARbACE IgG to Glomeruli Obtained from Isolated Perfused Kidneys of Normal Rabbits Untreated or Receiving Captopril for $8 d$

\begin{tabular}{lllll}
\hline $\begin{array}{l}\text { Number } \\
\text { of rabbits }\end{array}$ & $\begin{array}{l}\text { Captopril } \\
\text { adminis- } \\
\text { tration }\end{array}$ & $\begin{array}{l}\text { Binding of } \\
\text { GtARbACE IgG }\end{array}$ & $\begin{array}{l}\text { Binding of } \\
\text { normal goat IgG }\end{array}$ & $\begin{array}{l}\text { Specific binding } \\
\text { of GtARbACE IgG }\end{array}$ \\
\hline & & $\mu g / 10^{4}$ glomeruli & $\mu g / 10^{4}$ glomeruli & $\mu g / 10^{4}$ glomeruli \\
3 & No & $4.87 \pm 0.20$ & $0.74 \pm 0.57$ & $4.13 \pm 0.38$ \\
4 & Yes & $11.07 \pm 1.32^{*}$ & $1.74 \pm 0.98$ & $9.33 \pm 0.61^{\ddagger}$
\end{tabular}

* Statistically significant $(P<0.01)$ by Student's $t$ test when compared with the value obtained in untreated rabbits.

${ }^{\ddagger}$ Statistically significant $(P<0.001)$ by Student's $t$ test when compared with the value obtained in untreated rabbits.

of finely granular deposits, in the lamina rara externa. By light microscopy the glomeruli appeared normal. The study by transmission electron microscopy revealed a residual swelling in the endothelium, and irregularities and small foreign deposits on the epithelial side of the basement membrane (Fig. 15). The lesions detectable in rabbits treated with Captopril did not differ, in any stage of the disease, from those seen in untreated rabbits. The kidneys of rabbits injected with normal goat $\boldsymbol{\gamma}$-globulin (group I) or normal goat IgG (group II) had no abnormalities detectable by IF and immunoelectron microscopy (Fig. 14) or by morphological techniques. Likewise, the kidneys of rabbits injected with Fab fragments derived from GtARbACE IgG and from normal goat IgG (group III) appeared consistently normal.

Lesions characteristic of membranous glomerulonephritis were found in the kidneys of all rabbits in group IV. Diffuse, granular deposits of BSA, rabbit IgG and rabbit C3 were present along glomerular capillary walls (9), corresponding to subepithelial foreign deposits seen by electron microscopy. All eight rabbits injected with GtARbACE $\boldsymbol{\gamma}$-globulin had large, diffuse, granular deposits of goat IgG (Fig. 18); two of these rabbits had comparable deposits of ACE (Fig. 19). Deposits of goat IgG or $A C E$ were never found in the kidneys removed before the injection of GtARbACE $\gamma$-globulin. Likewise, deposits of goat IgG and ACE were never seen in the kidneys of the three rabbits injected with normal goat $\gamma$-globulin.

Circulating antibodies, reactivity of glomerular eluates, and circulating antigen-antibody complexes. These studies were performed in rabbits of group I (Table I). GtARbACE antibodies were shown by indirect IF technique during the first 6 or $7 \mathrm{~d}$ of the experiment in all sera tested, and were undetectable thereafter. Rabbit anti-goat IgG was first detectable by ELISA technique in the sera of all rabbits on day 7 (in one rabbit only on day 5) and was then demonstrable until sacrifice. In rabbits injected with normal goat $\boldsymbol{\gamma}$-globulin the clearance of normal goat $\gamma$-globulin and the development of the autologous response of this foreign protein had patterns identical to those observed in rabbits injected with the immune preparation. The $\gamma$-globulins eluted from glomeruli of rabbits injected with GtARbACE $\gamma$ globulin reacted with rabbit $\mathrm{ACE}$. In contrast, the eluate obtained from glomeruli of rabbits injected with normal goat $\gamma$-globulin did not show ACE reactivity.

The Raji cell radioimmunoassay demonstrated the appearance of immune complexlike material in the circulation of all rabbits in group I on day 6-8. These levels remained elevated until day 24. There was no difference between the levels of circulating immune complexes detected in rabbits injected with GtARbACE $\boldsymbol{\gamma}$-globulin or injected with normal goat $\boldsymbol{\gamma}$-globulin.

Proteinuria. In the majority of rabbits in groups I, II, and III, injected with GtARbACE $\gamma$-globulin or IgG, as well as in rabbits injected with Fab fragments or with normal goat IgG the urinary protein excretion was normal $(20-40 \mathrm{mg} / 24 \mathrm{~h})$. Only three rabbits receiving Captopril and injected with GtARbACE $\gamma$-globulin had a mild (100-200 mg/24 h) and transient (day 2 or 3 ) proteinuria. In two of these animals the increased glomerular permeability was associated with mild and transient binding of goat IgG to the brush border of proximal tubules. All rabbits injected with cationized BSA (group IV) developed proteinuria that, before unilateral nephrectomy, was $>300 \mathrm{mg} / \mathrm{dl}$.

\section{Discussion}

The results of this study show that heterologous divalent ACE antibodies induce an in vivo redistribution of $A C E$ on the surface of endothelial cells. Using different experimental protocols we demonstrate that the effects of the same antibody-antigen interaction is dependent upon the prevailing pathophysiological conditions in the kidney. To analyze the consequences of antibodyACE interaction at glomerular level we used four different experimental protocols: (a) expression of ACE in cultured glomerular epithelial cells, and in glomeruli present in kidney sections; (b) perfusion of isolated kidneys with GtARbACE antibodies; $(c)$ injection of GtARbACE antibodies into the abdominal aorta or into an ear vein in normal rabbits; and $(d)$ injection of GtARbACE antibodies into an ear vein in proteinuric rabbits.

First, we were not able to detect ACE by the IF technique on cultured glomerular epithelial cells or in glomeruli in sections of renal tissue. When glomerular epithelial cells were exposed to, or rabbits received, Captopril-an ACE inhibitor able to elicit, or to increase, the expression of ACE in rat lung $(37,38)$ and in cells in culture (18)-the results were the same. Immunohistological studies designed to demonstrate presence of ACE in glomeruli of various mammals have provided positive (39-41) or negative (42-44) results. This discrepancy may be ascribed to the very small amount of ACE measurable by biochemical methods in renal glomeruli, as compared to other structures (45).

Second, the experiments of perfusion of isolated kidneys showed that ACE was rapidly redistributed by divalent GtARbACE antibodies to form immune aggregates at the surface of glomerular endothelial cells, a phenomenon analogous to "patching" (46). Assuming that the number of rabbit glomeruli is approximately 80,000 (47) we calculate only $33 \mu \mathrm{g}$ of GtARbACE IgG was specifically bound. Captopril elicited a twofold increase in ACE expression, comparable to the increase previously reported in rat lung homogenates $(37,38)$, but less than the 6- to 16-fold increase measured in cultured human endothelial cells (18). Though comparisons are difficult due to differences in the techniques used, the binding capacity of GtARbACE IgG appeared to be considerably less than that of heterologous glomerular basement membrane antibodies (up to $1,000 \mu \mathrm{g})(48)$, and also less than to the binding of Heymann antibodies (80-100 $\mu \mathrm{g})(20)$. Thus the concentration of ACE in the glomerular endothelium is probably close to the limit of sensitivity of conventional immunohistological techniques.

Third, the injection of divalent GtARbACE antibodies into 

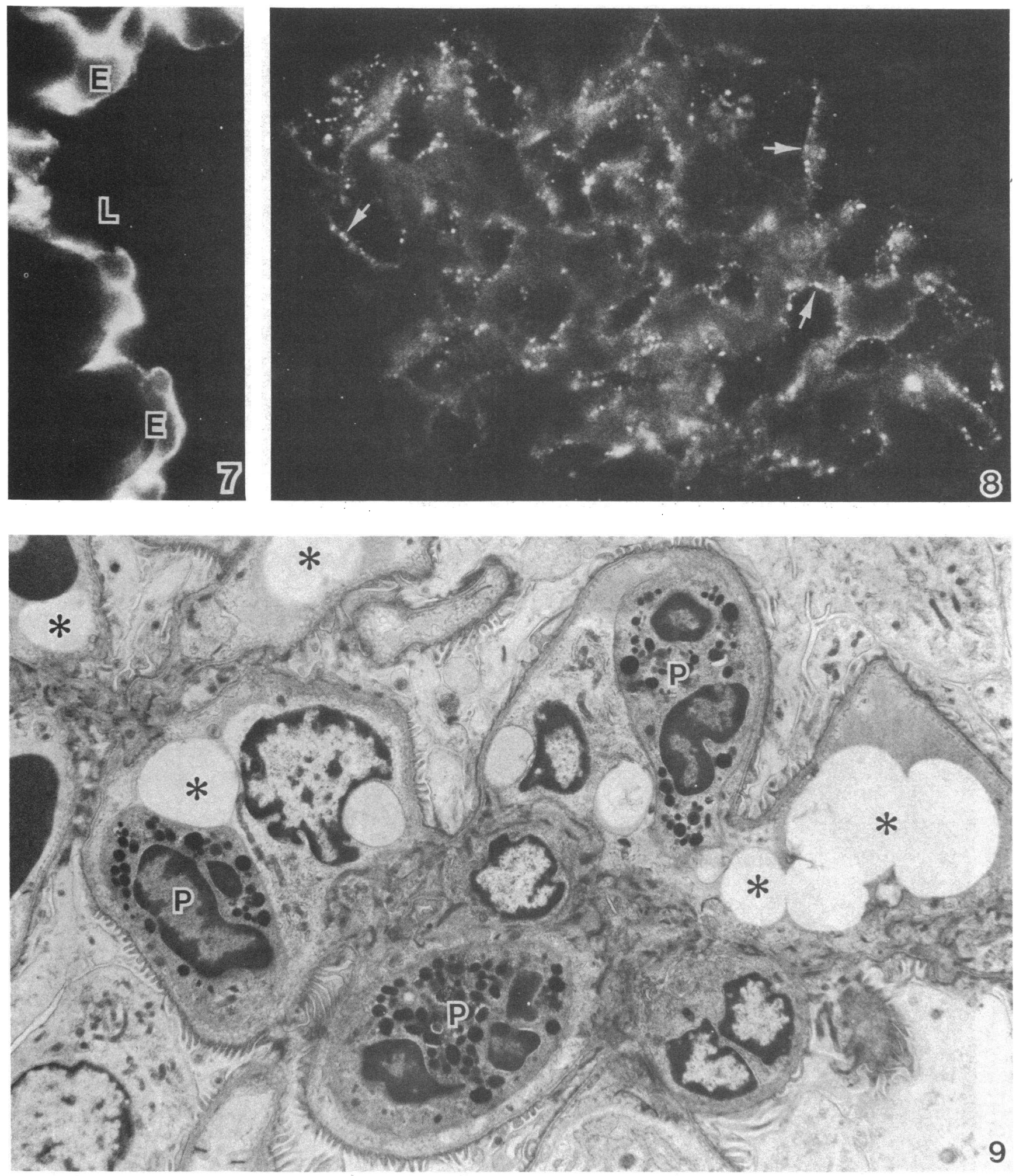

Figures 7 through 9. (Fig. 7) Renal artery from a rabbit perfused with GtARbACE IgG (see Fig. 5), and stained with FITC-rabbit anti-goat IgG. Deposits of goat IgG are present on the plasma membrane of endothelial cells $(E)$. L, arterial lumen. $\times 1,200$. (Fig. 8) IF micrograph of a renal glomerulus 1 day after intravenous injection of GtARbACE IgG. Fine, granular, deposits of goat IgG (arrows) are present along the inner part of the capillary walls. $\times 1,000$. (Fig. 9) Electron micrograph of a renal glomerulus, 1 day after intravenous injection of GtARbACE $\gamma$-globulin. The lumina of the capillaries are obliterated by polymorphonuclear leukocytes $(P)$ and by large endothelial blebs $(*) . \times 7,000$. 

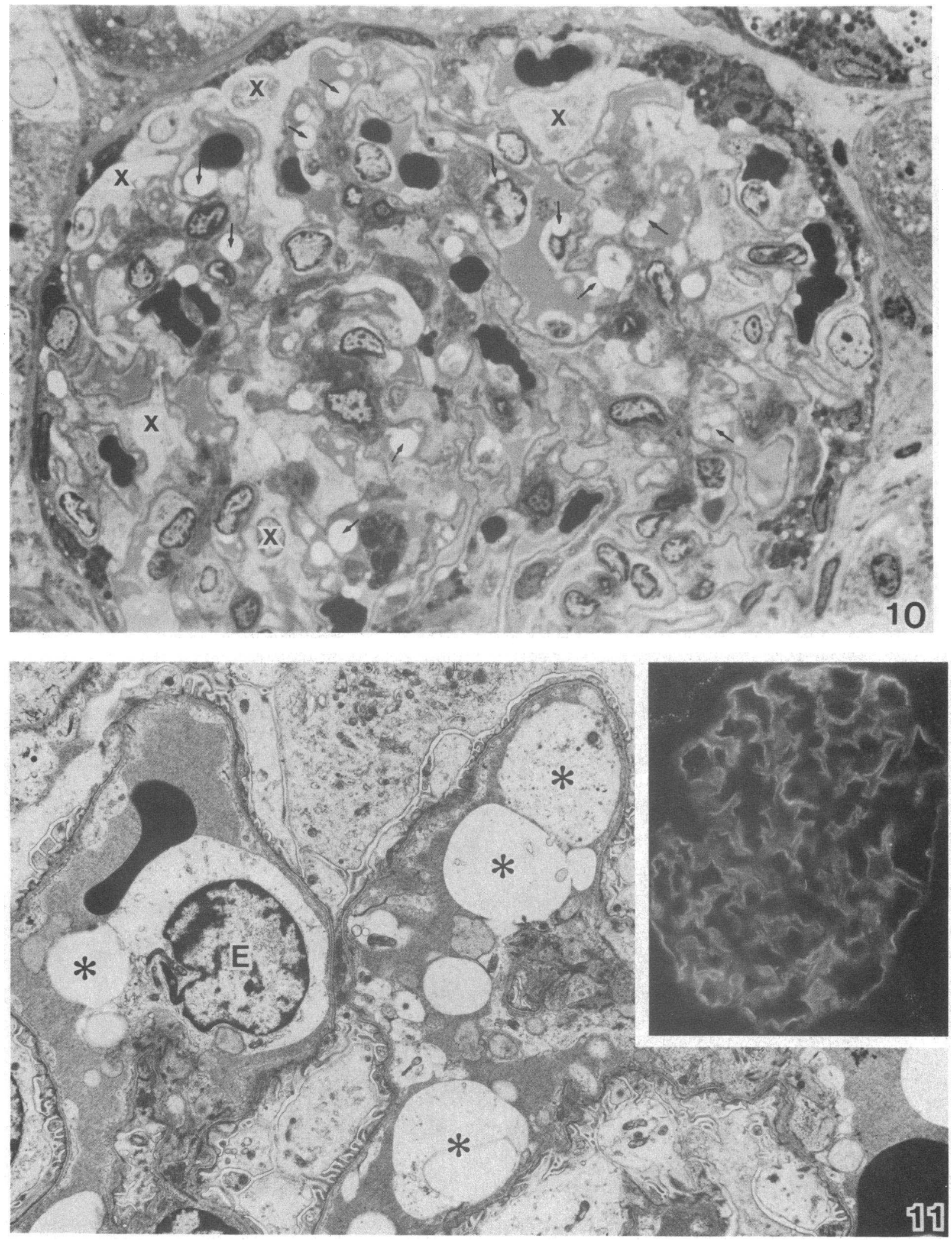

Figure 10. Light micrograph showing a renal glomerulus, after $4 \mathrm{~d}$ of intravenous injections of GtARbACE $\gamma$-globulin. The lumina of the capillaries are obliterated by blebs (arrows) of the endothelial cells. The cytoplasm of the visceral epithelial cells $(x)$ are pale and devoid of organelles. $\times 1,200$.

Figure 11. Electron micrograph of a renal glomerulus after 4 days of intravenous injections of GtARbACE $\gamma$-globulin. The endothelial cells $(E)$ are swollen and devoid of cytoplasmic organelles (*). The lumina of the capillaries are partially obliterated by endothelial blebs. $\times 12,000$. The inset shows diffuse, almost linear, deposits of goat IgG along the glomerular capillary walls, $4 \mathrm{~d}$ after injection of GtARbACE $\gamma$-globulin. $\times 400$. 

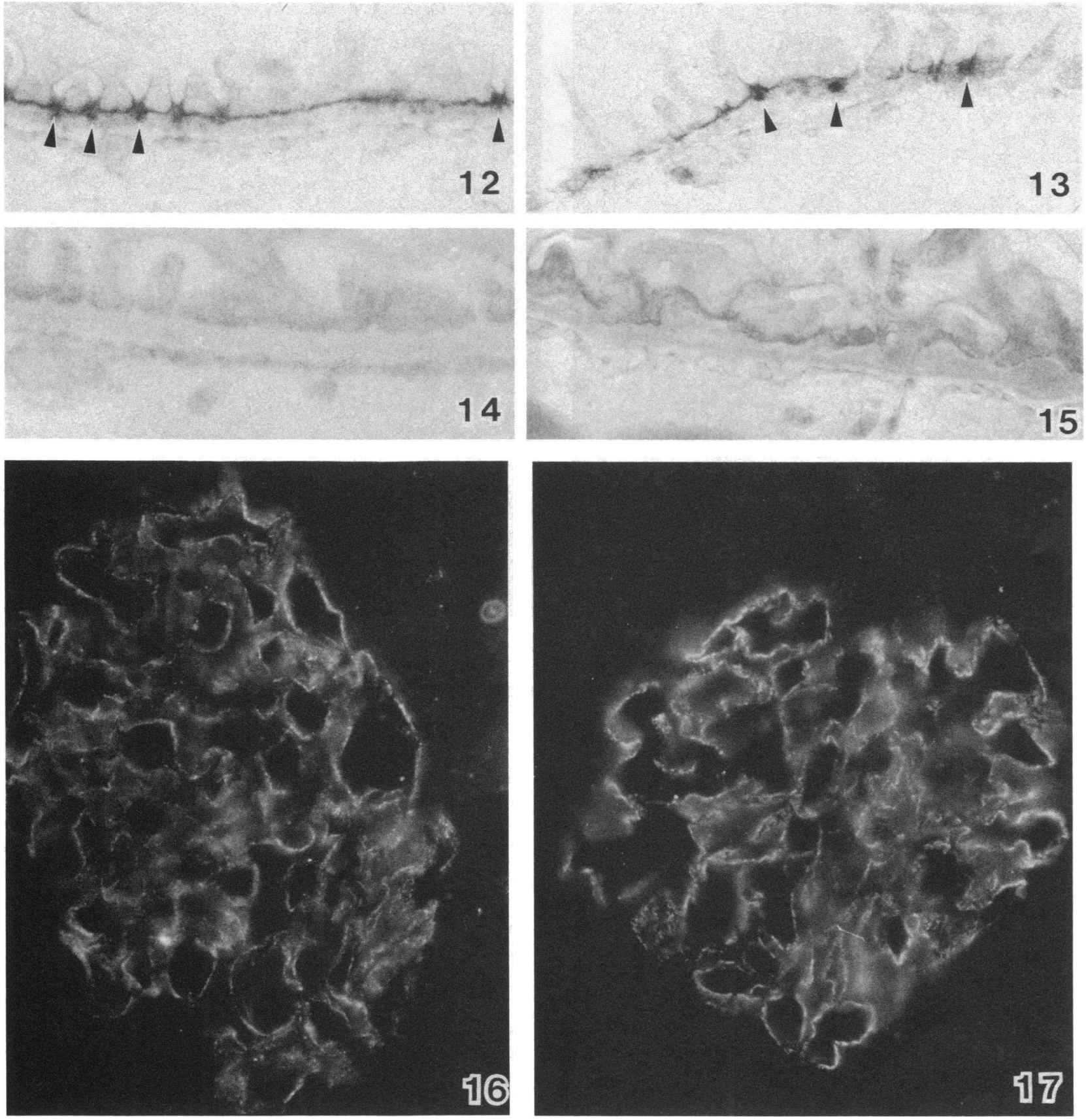

Figures 12 through 14. Electron micrographs showing results of experiments performed by immunoperoxidase technique. Deposits (arrowheads) of goat IgG are present within or near the epithelial filtration slits at day 3 (Fig. 12), and day 24 (Fig. 13), respectively. Fig. 14 shows the result obtained in a rabbit injected with normal goat IgG. $\times 30,000$.

Figures 15 through 17. (Fig. 15) Transmission electron micrograph showing irregularities or small foreign deposits on the epithelial side of the glomerular basement membrane at day 24. $\times 30,000$. (Fig. 16) IF micrograph showing fine, granular, deposits of rabbit IgG along the glomerular capillary wall of a rabbit, $20 \mathrm{~d}$ after injection of GtARbACE $\gamma$-globulin. $\times 800$. (Fig. 17) IF micrograph showing fine, granular, deposits of rabbit $\mathrm{C} 3$ along the glomerular capillary wall of a rabbit, $20 \mathrm{~d}$ after injection of GtARbACE $\gamma$-globulin. $\times 800$.

the abdominal aorta or into an ear vein in normal rabbits induced a mild and transient, but consistently reproducible and well defined, nephrotoxic glomerulonephritis. Two factors could account for the benign nature of this new disease: the small amount of ACE expressed on the glomerular endothelium, and the position of ACE, a plasma membrane antigen, in the capillary walls, and the fate of the immune complexes. In nephrotoxic glomerulonephritis the factor determining the severity of the heterologous phase is the amount of heterologous antibodies "plantable" in the glomerular capillary walls (48) and, as said above, this amount was small $(\sim 33 \mu \mathrm{g})$. The other factor was the dynamic character of the ligand-cell surface antigen inter- 

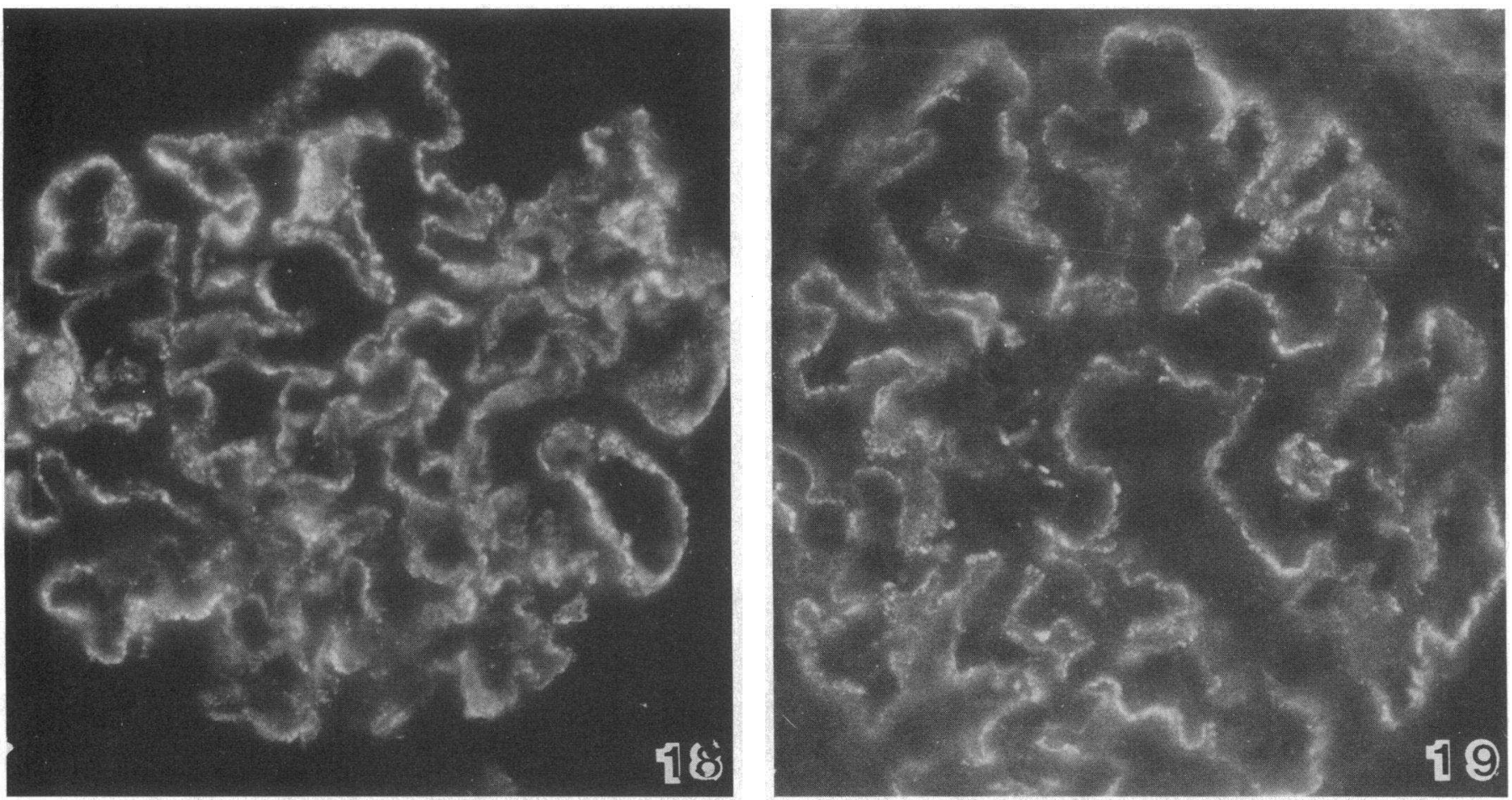

Figures 18 and 19. IF micrograph showing granular deposits of goat IgG along the glomerular capillary walls of a rabbit with membranous glomerulonephritis induced by cationized BSA, after $4 \mathrm{~d}$ of injection of GtARbACE $\gamma$-globulin. $\times 800$. (Fig. 19) IF micrograph showing granular deposits of rabbit ACE along the glomerular capillary walls of the rabbit illustrated in Fig. 18. $\times 900$.

action (46). Like in the experiments of perfusion of isolated kidneys, when divalent GtARbACE antibodies were injected intravenously, discrete, granular, deposits of goat IgG became immediately detectable at the surface of glomerular endothelial cells, suggesting a rapid redistribution of ACE in the fluid phase of the cell membrane, with aggregation of immune complexes (patching), and subsequent disappearance of immune complexes from the cell surface, analogous to "shedding" (46). Deposits of ACE were not detectable by direct IF technique, presumably because relatively few ACE molecules were covered by an excess of antibody. The disappearance of the antigen from the cell surface ("antigenic modulation") $(49,50)$ explains the short duration of the heterologous phase, which reached a peak on day 1 and abated on day 2. A similar effect is observed in the lung where divalent ACE antibodies induce resistance to further inflammatory injury through antigenic modulation (11). The observation that intracapillary exudative and degenerative lesions were restricted to day 1 and 2 is consistent with results of other studies showing that intracapillary inflammatory changes preferentially occur when antibodies react with antigens proximal to the circulation (51).

From day 3 onward the deposits of goat IgG, seen by IF microscopy, became diffuse and almost linear, corresponding to deposits of reaction product seen by immunoelectron microscopy at the base of the foot processes and in the filtration slits. The deposits of $\mathrm{C} 3$ disappeared and the intracapillary exudative changes subsided. It was only after day 8 that finely granular deposits of rabbit IgG and $\mathrm{C} 3$ became detectable, together with goat IgG, in the subepithelial part of the glomerular basement membrane. The failure to demonstrate antibody to goat IgG or immune complexes in the circulation before day 6 or 7 , the constant absence of subepithelial deposits of rabbit $\mathrm{IgG}$ at day 3 , the demonstration that the $\gamma$-globulins eluted from glomeruli of rabbits injected with GtARbACE $\gamma$-globulin had ACE reactivity, and the absence of immune deposits throughout the course of the study in glomeruli of rabbits injected with GtARbACE Fab or with normal goat IgG, convincingly argue against the hypothesis that the subepithelial immune deposits were formed by circulating goat IgG-rabbit anti-goat IgG complexes, unrelated to ACE. The most plausible explanation for the appearance on day 3 of immunohistological aspects reminiscent of Heymann glomerulonephritis is that $\mathrm{ACE}$ immune complexes formed at the luminal surface of the endothelium were forced across the basement membranes by hydrodynamic forces of filtration. This migration may be favored by increased vascular permeability induced by potent vasoactive polar lipids, such as platelet activating factor released from polymorphonuclear leukocytes (52) or from stimulated endothelial cells $(53,54)$. Support for this explanation comes from studies in passive Heymann glomerulonephritis induced by heterologous antibodies to unpurified tubular brush border antigens where an early antigen-antibody reaction at the level of the endothelium of glomerular capillaries, with rapid disappearance of endothelial antigen(s), and a subsequent development of subepithelial immune deposits have been described (55). These antisera may contain antibodies reactive with endothelia, including the glomerular endothelium (56-63). Other studies, concerning soluble antigens, provide additional evidence that immune complexes formed at the luminal side of the capillary wall migrate toward the epithelial side of the glomerular basement membrane (64-66). The alternative 
possibility, that at least part of the deposits of goat IgG seen from day 3 in the subepithelial part of the basement membrane represented Heymann-like immune complexes generated by interaction of GtARbACE antibodies with ACE expressed at the level of the podocytes, was not substantiated by the results of our study, including those in cultured glomerular visceral epithelial cells.

From day 8 to the end of the observation period the salient pathologic feature was the development of an autologous phase characterized by strong linear and segmental deposits of rabbit IgG and C3, and weaker deposits of goat IgG, at the base of the foot processes and in the filtration slits. These changes resemble those seen in the early stages of passive Heymann glomerulonephritis $(2,67)$. The control experiments excluded the possibility that these lesions resulted from serum sickness (68) induced by administration of heterologous IgG or from artifacts inherent to the immunoperoxidase technique (27). With this assurance, the most likely cause of the subepithelial changes is the reaction of rabbit antibody, and complement, with goat IgG planted by hydrodynamic forces in the subepithelial part of the glomerular capillary wall. Lack of progression of glomerular injury is probably related to an insufficient amount of "planted" goat IgG (69).

Fourth, when divalent GtARbACE antibodies were injected into a vein of the ear in rabbits rendered proteinuric by multiple immunizations with cationized BSA, large deposits of goat IgG and rabbit $\mathrm{ACE}$, presumably immune complexes, were found in glomerular subepithelial deposits. Our results do not establish the origin of these ACE-immune complexes. It seems unlikely, however, that they were shed exclusively from the glomerular endothelium. In contrast, it appears reasonable to think that, according to classical notions (68), the local increase in permeability may have facilitated the localization of immune complexes shed from vascular beds (lung) abundantly endowed with ACE (39). If this hypothesis is confirmed these results will provide new evidence that autologous extrarenal antigens can localize in renal glomeruli. Furthermore, the results will confer compelling force to the claim that glomerular subepithelial immune deposits can be induced by immune complexes formed, or shed, in the circulation (70).

In conclusion, this study describes glomerular changes resulting from an interaction occurring between an antigen expressed on the surface of endothelial cells and circulating antibody. Due to the paucity of expression of the antigen and properties of plasma membrane molecules this interaction induces only a mild and transient inflammatory lesion. Its theoretical and practical importance, however, is that vascular injury can result from antibodies reactive with multiple epitopes in various layers of the capillary walls, and endothelial antigens may contribute to the expression of immunologic disease.

\section{Acknowledgments}

The authors thank Mr. Neal Niesen for expert microsurgery, Ms. Lourdes T. Fernandez, Mrs. Irene Pawlowski, Mr. Bruce Luders, and Mr. Gerald Verdi, for technical assistance, Mrs. Marilyn Fitzsimmons for typing the manuscript, The Squibb Institute for Medical Research, Princeton, NJ, and Mr. S. J. Lucania for the generous gift of Captopril.

This work was supported by grants AI-10334 and AM-36807 of the National Institutes of Health, United States Public Health Service, and by grants from the American Heart Association, the Joe and Emily Lowe Foundation and the Dana Foundation.

\section{References}

1. Unanue, E. R., and F. J. Dixon. 1967. Experimental glomerulonephritis: immunological events and pathogenetic mechanisms. $A d v$. Immunol. 6:1-90.

2. Barabas, A. Z., and R. Lannigan. 1974. Induction of an autologous immune complex glomerulonephritis in the rat by intravenous injection of heterologous anti-rat kidney tubular antibody. I. Production of chronic and progressive immune complex glomerulonephritis. Br. J. Exp. Pathol. 55:47-55.

3. Van Damme, D. J., G. T. Fleuren, W. W. Bakker, R. L. Vernier, and J. Hoedemaeker. 1978. Experimental glomerulonephritis in the rat induced by antibodies directed against tubular antigens. V. Fixed glomerular antigens in the pathogenesis of heterologous immune complex glomerulonephritis. Lab. Invest. 38:502-510.

4. Couser, W. G., D. R. Steinmuller, M. M. Stilmant, D. Salant, and L. M. Lowenstein. 1978. Experimental glomerulonephritis in the isolated perfused rat kidney. J. Clin. Invest. 62:1275-1287.

5. Kerjaschki, D., and M. G. Farquhar. 1982. The pathogenic antigen of Heymann nephritis is a membrane glycoprotein of the renal proximal tubule brush border. Proc. Natl. Acad. Sci. USA. 79:5557-5561.

6. Kerjaschki, D., and M. G. Farquhar. 1983. Immunocytochemical localization of the Heymann nephritis antigen (gp330) in glomerular epithelial cells of normal Lewis rats. J. Exp. Med. 157:667-686.

7. Giles, G. R., H. J. Boehmig, J. Lilly, H. Amemiya, H. Takagi, A. J. Coburg, W. E. Hathaway, C. B. Wilson, F. J. Dixon, and T. E. Starzl. 1970. Mechanism and modification of rejection of heterografts between divergent species. Transplant. Proc. 2:522-538.

8. Ito, S., G. Camussi, C. Tetta, F. Milgrom, and G. Andres. 1984. Hyperacute renal allograft rejection in the rabbit. The role of platelet activating factor and of cationic proteins derived from polymorphonuclear leukocytes and from platelets. Lab. Invest. 51:148-161.

9. Border, W. A., J. Ward, E. S. Kamil, and A. H. Cohen. 1982. Induction of membranous nephropathy in rabbits by administration of an exogenous cationic antigen. J. Clin. Invest. 69:451-461.

10. Caldwell, P. R. B., J. H. Wigger, L. T. Fernandez, R. M. D'Alisa, D. Tse-Eng, V. P. Butler, Jr., and I. Gigli. 1981. Lung injury induced by antibody fragments to angiotensin converting enzyme. Am. J. Pathol. 105:54-63.

11. Barba, L. M., P. R. B. Caldwell, G. H. Downie, G. Camussi, J. R. Brentjens, and G. Andres. 1983. Lung injury mediated by antibodies to endothelium. I. In the rabbit a repeated interaction of heterologous anti-angiotensin-converting enzyme antibodies with alveolar endothelium results in resistance to immune injury through antigenic modulation. $J$. Exp. Med. 158:2141-2158.

12. Taub, M. L. 1985. Primary culture of proximal tubule cells in defined medium. J. Tissue Culture Methods. 9:67-71.

13. Kearney, J. F., A. Radbruch, B. Leisegang, and K. Raijewsky. 1979. A new mouse myeloma cell line that has lost immunoglobulin expression but permits the construction of antibody-secreting hybrid cell lines. J. Immunol. 123:1548-1550.

14. Soon, D. C., N. Alavi, D. Livingston, S. Hiller, and M. Taub. 1982. Characterization of the primary rabbit kidney cultures that express proximal tubule functions in a hormonally defined medium. J. Cell Biol. 95:118-126. .

15. Kreisberg, J. I., R. L. Hoover, and M. J. Karnovsky. 1978. Isolation and characterization of rat glomerular epithelial cells in vitro. Kidney Int. 14:21-31.

16. Camussi, G., J. R. Brentjens, B. Noble, D. Kerjaschki, F. Malavasi, O. A. Roholt, M. G. Farquhar, and G. Andres. 1985. Antibody-induced redistribution of Heymann antigen on the surface of culture glomerular visceral epithelial cells: possible role in the pathogenesis of Heymann glomerulonephritis. J. Immunol. 135:2409-2416.

17. Striker, G. E. and L. J. Striker. 1985. Biology of disease. Glomerular cell culture. Lab. Invest. 53:122-131.

18. Fyhrquist, F., L. Hortling, and C. Grönhagen-Riska. 1982. In- 
duction of angiotensin I-converting enzyme by Captopril in culture human endothelial cell. J. Clin. Endocrinol. Metab. 55:783-786.

19. McConahey, P. J., and F. J. Dixon. 1966. A method of trace iodination of proteins for immunologic studies. Int. Arch. Allergy Appl. Immunol. 29:185-189.

20. Salant, D. J., C. Darby, and W. G. Couser. 1980. Experimental membranous glomerulonephritis in rats. Quantitative studies of glomerular immune deposit formation in isolated glomeruli and whole aminals. J. Clin. Invest. 66:71-81.

21. Jennings, L., O. A. Roholt, D. Pressman, M. Blau, G. A. Andres, and J. R. Brentjens. 1981. Experimental anti-alveolar basement membrane antibody-mediated pneumonitis. I. The role of increased permeability of the alveolar capillary wall induced by oxygen. J. Immunol. 127:129-134.

22. Wood, B. T., S. H. Thompson, and G. Goldstein. 1965. Fluorescent antibody staining. III. Preparation of fluorescein-isothiocyanatelabeled antibodies. J. Immunol. 95:225-229.

23. Andres, G. A., L. Accinni, S. M. Beiser, C. L. Christian, G. A Cinotti, B. F. Erlanger, K. C. Hsu, and B. C. Seegal. 1979. Localization of fluorescein labeled antinucleoside antibodies in glomeruli of patients with active systemic lupus erythematosus nephritis. J. Clin. Invest. 49: 2106-2118.

24. Platt, J. L., and A. F. Michael. 1983. Retardation of fading and enhancement of intensity of immunofluorescence by p-phenylenediamine. J. Histochem. Cytochem. 31:840-841.

25. McLean, I. W., and P. K. Nakane. 1974. Periodate-lysin-paraformaldehyde fixative. A new fixative for immunoelectron microscopy. J. Histochem. Cytochem. 22:1077-1083.

26. Graham, R. C., Jr., and M. J. Karnovsky. 1966. The early stages of absorption of injected horseradish-peroxidase in the proximal convoluted tubules of mouse kidney: ultrastructural cytochemistry by a new technique. J. Histochem. Cytochem. 14:291-302.

27. Courtoy, P. J., D. H. Picton, and M. G. Farquhar. 1983. Resolution and limitations of the immunoperoxidase procedure in the localization of extracellular matrix antigens. J. Histochem. Cytochem. 31: 945-951.

28. Nakane, P. K., and A. Kawaoi. 1974. Peroxidase-labeled antibody: a new method of conjugation. J. Histochem. Cytochem. 22:1084-1091.

29. Karnovsky, M. J. 1965. Formaldehyde-glutaraldehyde fixative of high osmolarity for use in electron microscopy. J. Cell Biol. 27:137A.

30. Krakower, C. A., and S. A. Greenspan. 1951. Localization of the nephrotoxic antigen within the isolated renal glomerulus. A.M.A. Arch. Pathol. 51:629-639.

31. Woodroffe, A. J., and C. B. Wilson. 1977. An evaluation of elution techniques in the study of immune complex glomerulonephritis. J. Immunol. 118:1788-1794.

32. Engvall, E., and P. Perlmann, 1972. Enzyme-linked immunosorbent assay, ELISA. J. Immunol. 109:129-135.

33. Pantoliano, M. W., B. Holmquist, and J. F. Riordan. 1984. Affinity chromatographic purification of angiotensin converting enzyme. Biochemistry. 23:1037-1042.

34. Theofilopoulos, A. N., C. B. Wilson, and F. J. Dixon. 1976. The Raji cell radioimmune assay for detecting immune complexes in human sera. J. Clin. Invest. 57:169-182.

35. Donker, A. J., R. C. Venuto, A. O. Vladutiu, J. R. Brentjens, and G. A. Andres. 1984. Effects of prolonged administration of D-penicillamine or Captopril in various strains of rats. Clin. Immunol. Immunopathol. 30:142-155.

36. Weichselbaum, T. E. 1946. An accurate and rapid method for the determination of proteins in small amounts of blood serum and plasma. Am. J. Clin. Pathol. 10:40-46.

37. Fyhrquist, F., T. Forslund, I. Tikkanen, and C. Grönhagen-Riska. 1980. Induction of angiotensin I-converting enzyme in rat lung with Captopril (SQ 14225). Eur. J. Pharmacol. 67:473-475.

38. Kokubu, T., E. Ueda, M. Ono, T. Kawabe, Y. Hayashi, and T. Kan. 1980. Effects of Captopril (SQ 14225) on the renin-angiotensinaldosterone system in normal rats. Eur. J. Pharmacol. 62:269-275.
39. Caldwell, P. R. B., B. C. Seegal, K. C. Hsu, and R. L. Soffer. 1976. Angiotensin-converting enzyme: vascular endothelial localization. Science (Wash. DC). 191:1050-1051.

40. Hall, E. R., J. Kato, E. G. Erdös, C. J. G. Robinson, and G. Oshima. 1976. Angiotensin I-converting enzyme in the nephron. Life Sci. 18:1299-1304.

41. McCormick, J. R., R. S. Thrall, A. Kerlin, and P. A. Ward. 1980. In vitro and in vivo effects of antibody to rat angiotensin converting enzyme. Clin. Immunol. Immunopathol. 15:444-455.

42. Taugner, R., E. Hackenthal, E. Rix, R. Nobling, and K. Poulsen. 1982. Immunocytochemistry of the renin-angiotensin system: renin, angiotensinogen, angiotensin I, angiotensin II, and converting enzyme in the kidneys of mice, rats and tree shrews. Kidney Int. 22:S33-S34.

43. Takada, Y., K. Hiwada, M. Unno, and T. Kokubu. 1983. Immunocytochemical localization of angiotensin converting enzyme at the ultrastructural level in the human lung and kidney. Biomed. Res. 3:169172.

44. Brunevald, P., N. Hinglais, F. Alhenc-Gelas, V. Tricottet, P. Carvol, J. Menard, J. P. Camilleri, and J. Bariety. 1986. Angiotensin I converting enzyme in human intestine and kidney. Histochemistry. 85:7380 .

45. Ward, P. E., W. Schultz, R. C. Reynolds, and E. G. Erdös. 1977. Metabolism of kinins and angiotensins in the isolated glomerulus and brush border of the rat kidney. Lab. Invest. 36:599-606.

46. Schreiner, G. F., and E. R. Unanue. 1976. Membrane and cytoplasmic changes in B lymphocytes induced by ligand-surface immunoglobulin interaction. Adv. Immunol. 24:37-165.

47. Strassberg, J., J. Paule, H. C. Gonick, M. H. Maxwel, and C. R. Kleeman. 1967. The quantitative estimation of perfusible glomeruli and the collagen and non-collagen nitrogen of the normal kidney. Nephron. 4:384-393.

48. Unanue, E. R., and F. J. Dixon. 1965. Experimental glomerulonephritis. V. Studies on the interaction of nephrotoxic antibodies with tissues of the rat. J. Exp. Med. 121:697-714.

49. Boyse, E. A., E. Stockert, and L. J. Old. 1967. Modification of the antigenic structure of the cell membrane by thymus-leukemia (TL) antibody. Proc. Natl. Acad. Sci. USA. 58:954-957.

50. Old, L. J., E. Stockert, E. A. Boyse, and J. H. Kim. 1968. Antigenic modulation. Loss of TL antigen from cells exposed to TL antibody. Study of the phenomenon in vitro. J. Exp. Med. 127:523-539.

51. Salant, D. J., S. Adler, C. Darby, N. J. Capparel, G. C. Groggel, I. D. Feintzeig, H. G. Rennke, and J. E. Dittmer. 1985. Influence of antigen distribution on the mediation of immunological glomerular injury. Kidney Int. 27:938-950.

52. Lynch, J. M., G. Z. Lotner, S. J. Betz, and P. M. Henson. 1979. The release of platelet-activating factor by stimulated rabbit neutrophils. J. Immunol. 123:1219-1226.

53. Camussi, G., I. Pawlowski, F. Bussolino, P. R. B. Caldwell, J. Brentjens, and G. Andres. 1983. Release of platelet activating factor in rabbits with antibody-mediated injury of the lung: the role of leukocytes and of pulmonary endothelial cells. J. Immunol. 131:1802-1807.

54. Camussi, G., M. Aglietta, F. Malavasi, C. Tetta, W. Piacibello, F. Sanavio, and F. Bussolino. 1983. The release of platelet-activating factor from human endothelial cells in culture. J. Immunol. 131:23972403.

55. Jeraj, K., R. L. Vernier, S. P. Sisson, and A. F. Michael. 1984. A new glomerular antigen in passive Heymann's nephritis. Br. J. Exp. Pathol. 65:485-498.

56. Ronco, P., L. Allegri, C. Melcion, E. Pirotsky, M. D. Appay, J. Bariety, F. Pontillo, and P. Verroust. 1984. A monoclonal antibody to brush border and passive Heymann nephritis. Clin. Exp. Immunol. 55: 319-332.

57. Ronco, P., C. Melcion, M. Geniteau, E. Ronco, L. Reiningeu, M. Golceran, and P. Verroust. 1984. Production and characterization of monoclonal antibodies against rat brush border antigens of the proximal convoluted tubule. Immunology. 53:87-95.

58. Kerjaschki, D., D. J. Sharkey, and M. G. Farquhar. 1984. Iden- 
tification and characterization of podocalyxin, the major sialoprotein of renal glomerular epithelial cells. J. Cell Biol. 98:1591-1596.

59. Bhan, A. K., E. E. Schneeberger, L. G. Baird, B. A. Collins, K. Kamata, D. Bradford, M. E. Erikson, and R. T. McCluskey. 1985. Studies with monoclonal antibodies against brush border antigens in Heymann nephritis. Lab. Invest. 53:421-432.

60. Huang, T. W., and J. C. Langlois. 1985. Podoendin. A new cell surface protein of the podocyte and endothelium. J. Exp. Med. 162:245267.

61. Horvat, R., A. Hovorka, G. Dekan, H. Poczewski, and D. Kerjaschki. 1986. Endothelial cell membrane contains podocalyxin, the major sialoprotein of visceral glomerular epithelial cells. J. Cell Biol. 102:489491.

62. Bagchus, W. M., J. T. W. M. Vos, J. Hoedemaeker, and W. W. Bakker. 1986. The specificity of nephritogenic antibodies. III. Binding of anti-Fx1A antibodies in glomeruli is dependent on dual specificity. Clin. Exp. Immunol. 63:639-647.

63. Chatelet, F., E. Briant, P. Ronco, J. Roland, and P. Verroust. 1986. Ultrastructural localization by monoclonal antibodies of brush border antigens expressed by glomeruli. I. Renal distribution. Am. J. Pathol. 122:500-511.
64. Vogt, A., R. Rohrbach, F. Shimizu, H. Takamiya, and S. Batsford. 1982. Interaction of cationized antigen with rat glomerular basement membrane: In situ immune complex formation. Kidney Int. 22:27-35.

65. Agodoa, L. Y. C., J. V. Gauthier, and M. Mannik. 1983. Precipitating antigen-antibody systems are required for the formation of subepithelial electron-dense immune deposits in rat glomeruli. J. Exp. Med. 158:1259-1271.

66. Kaseda, N., Y. Uehara, Y. Yamamoto, and K. Tonaka. 1985. Induction of in situ immune complexes in rat glomeruli using avidin, a native cationic macromolecule. Br. J. Exp. Pathol. 66:729-736.

67. Sugisaki, T., J. Klassen, G. A. Andres, F. Milgrom, and R. T. McCluskey. 1973. Passive transfer of Heymann nephritis with serum. Kidney Int. 3:66-73.

68. Cochrane, C. G., and D. Koffler. 1973. Immune complex disease in experimental animals and man. Adv. Immunol. 16:185-264.

69. Unanue, E. R., and F. J. Dixon. 1965. Experimental glomerulonephritis. VI. The autologous phase of nephrotoxic serum nephritis. J. Exp. Med. 121:715-725.

70. Dixon, F. J. 1962-63. The role of antigen-antibody complexes in disease. Harvey Lect. 58:21-52. 